\section{'The only constant is change': UKSEM, ISEM, Twitter, Podcasts and YouTube reflect the dynamic nature of sport and exercise medicine}

\author{
Karim M Khan
}

David Bowie's 1971 classic song 'Changes' includes the lines 'Time may change me, but I can't trace time'. As a lapsed BASM (as it was then) member, I believe he was suggesting we could be heroes and that we should dance to the major changes we see today in BASEM, UKSEM, ISEM, Twitter and YouTube. For the more classically inclined, the Greek philosopher Heraclitus is responsible for the quote in the title of this article. So let's jump in the river!

\begin{abstract}
UKSEM
The acronym doesn't really roll off the tongue yet but it represents four incredible days of sport and exercise medicine in London this November (24-27). If you are reading this then the conference is for you-for innovation (new research), education (yours and also for sharing with students and colleagues) and for knowledge translation (turning research into action). Get a charge from the promotional video (http://www.uksem.org/). It will be the biggest sport and exercise medicine conference in Europe for 2010, with a stunning lineup at London's new Excel facility. Haskell, Ernst, Coyle, Coe, McCrory, Kjaer, Giles and more-30 speakers from seven countries. Put your helmet on and get down there!
\end{abstract}

Correspondence to Dr Karim M Khan, Centre for Hip Health and Mobility, Vancouver Costal Health Research Institute, University of British Columbia \& Department of Family Practice, Faculty of Medicine, University of British Columbia; 303-2647 Willow Street, Vancouver, V5Z 3P1, Canada;

karim.khan@ubc.ca

\section{ISEM}

UK's Institute of Sport and Exercise Medicine (David Patterson) have partnered with Arthritis Research UK (Alan Silman) to change the face of arthritis following exercise or sport (October 21 and 22). Does Sport and Exercise Help or Hinder in Arthritis? I'd market it as 'Joint Effusion? Avoid Confusion!' but my avatar gently advises I stick to my day job. What about 'For sport and exercise clinicians, this is the opportunity of the decade to hear from the international expert researchers and clinicians who'll help you with both treatment and prevention of arthritis relating to sport'. The link is http://sport. arthritisresearchuk.org/

\section{Twitter}

Imagine petit dejeuner in a Paris street cafe in summer. Passing your table, while at once balancing coffee, Le Monde and croissant, Richard Smith fires a quip, Roald Bahr a clinical tip, Mark Hutchinson the link to a video clip. You can juggle how much medicine and physiotherapy you want in your breakfast Twitter mix; you can weave it in alongside Iman's quotes, building boats and self-help notes. You can eavesdrop without angst. If the tweets are boring you just 'unfollow' and there will not be blood. BJSM's Twitter team shares practical, interesting and occasionally quirky links relevant to patient care and health policy. Set up your own Twitter World Cafe-there are fascinating folk out there! It's easy and even my mum (born 1927, shh! secret) just bought a laptop and proved that the future is not a foreign country.

\section{Podcasts}

If you were a space oddity who fell to earth podcasts would have to be the best innovation to take back far above the world. Podcasts are a cinch to access and fascinating because the experts have time to chat. This is more like private mentorship over breakfast! But you can be in your pyjamas, no makeup. You don't need an iPod, an iPad or an iPhone. Just the iDea. On the BJSM home page, click on Podcasts and then your favourite topic. You get expert answers to the following and more: Is 6 months too early to return to sport after ACL rupture? (http://podcasts. bmj.com/bjsm/2010/06/01/acl-injuries/ $? q=$ w_bjsm_podcast_tab), Is obesity the wrong target for public health? (http:// podcasts.bmj.com/bjsm/2010/08/16/ should-health-policy-focus - onphysical-activity-rather-than-obesity/). Role of cortisone and PRP in tendinopathy? How much can elite kids train? (http:// podcasts.bmj.com/bjsm/). The biggest names on the hot topics at your fingertips. Please request your dream podcast guest and we'll give it a shot (bjsm@ bmjgroup.com). PS: George Clooney is booked out for 2011 apparently.

\section{And YouTube...}

I could go on but they are calling stumps. In a word...see BJSM Videos (http://www. youtube.com/user/BJSMVideos), where Mark Hutchinson's physical examination series of clips has passed 1 million page views - the most watched series of physical examination clips in the history of the web (knee, shoulder, hip/groin).

$B J S M$ helps clinicians in sport and exercise medicine harness global expertise in a range of convenient digital formats. Our 1.5 million annual page downloads highlight that we are more than 16 annual issues alone. And hit those UKSEM and ISEM registration links before time runs out! See you next month, or preferably sooner on Twitter (@BJSportsMed_BMJ)!

Br J Sports Med 2010;44:911. doi:10.1136/bjsm.2010.079269 